\title{
Effect of stacking sequence on physical, mechanical and tribological properties of glass-carbon hybrid composites
}

\author{
Gaurav AGARWAL ${ }^{1, *}$, Amar PATNAIK ${ }^{2}$, Rajesh kumar SHARMA ${ }^{2}$, Jyoti AGARWAL ${ }^{3}$ \\ ${ }^{1}$ Department of Mechanical Engineering, Invertis University, Bareilly, India \\ ${ }^{2}$ Department of Mechanical Engineering, National Institute of Technology (NIT) Hamirpur, India \\ ${ }^{3}$ Department of Computer Engineering, Rajshree Institute of Management \&Technology (RIMT), Bareilly, India \\ Received: 30 May 2014 / Revised: 04 September 2014 / Accepted: 15 October 2014 \\ C The author(s) 2014. This article is published with open access at Springerlink.com
}

\begin{abstract}
A study was done to determine the effect of best stacking sequence (position and orientation) on the mechanical properties, friction and wear response of hybrid composites. The main purpose of the study was to determine the best available stacking sequence for which the physical, mechanical and three body abrasive wear rate is optimum. Test for mechanical properties (tensile strength, flexural strength, inter laminar shear strength, impact strength and hardness) was done on glass-carbon hybrid composites. The composites were then subjected to test for three body abrasive wear on a designed experimental setup. Five different factors (sliding velocity, fabric weight percentage, normal load, sliding distance and abrasive particle size) varied in steps to evaluate the friction and three body abrasive wear response of the composites. The design of experiment using Taguchi's orthogonal array and analysis of variance (ANOVA) was applied to find out minimum specific wear rate. The results revealed the significance in arrangement of two different layers of fabric (glass and carbon) and the difference in properties obtained by them. Using Taguchi experimental analysis it has been observed that three body abrasive wear rate is minimum at $72 \mathrm{~cm} / \mathrm{s}$ sliding velocity, $30 \mathrm{wt} . \%$ fabric content, $80 \mathrm{~N}$ normal load, $90 \mathrm{~m}$ sliding distance and $125 \mu \mathrm{m}$ abrasive particle size. The scanning electron microscope (SEM) studies revealed the dynamics of three-body abrasive wear and underlying micro-mechanisms that result in the analysis of three body abrasive wear.
\end{abstract}

Keywords: hybrid composite; stacking sequence; Taguchi's method; wear mechanism

\section{Introduction}

Polymer matrix composite is emerged as a better substitute for high strength and light weight applications. The continuous increasing demand for better substitute in newer dimensions gives rise to the increasing research in the field of composites. Strength and continuous use of composite material for particular applications depends on number of factors, i.e., by modifying specific factor needed for particular application which enhances the durability of the composite material [1, 2]. Check for mechanical

\footnotetext{
* Corresponding author: Gaurav AGARWAL.

E-mail: agarwal200@gmail.com
}

properties is essential in determining certain properties needed for various applications in the field of composites. Hybrid composites consist of two or more constituents of different phases mix in a certain fashion to form composites. Hybrid composite materials are designed for specific duty applications. The properties of composites can be improved by careful design of the hybrid configuration [3,4]. Commonly two or more different fibers or fibers and fillers are mixed/arranged together in certain fashion along with matrix to form composites because mixing two or more fibers or fiber-filler in matrix enhances the properties of the composites [5].

Two or more fibers and/or fiber and fillers are mixed together so as to get the advantages of both the 
fibers/fillers in terms of mechanical properties, thermal properties, and tribological properties (friction, wear, etc.) of the composites. The possible reason for enhanced properties is that fibers and fillers of specific characteristics mixed together in a certain pattern to provide desired properties which cannot be obtained by mixing individual fibers in the matrix [6]. Suresha et al. [7] observed that excellent tribological characteristics of carbon fiber reinforced in vinyl ester is due to thin film formation at the counter phase. Also it has been observed that the worn surfaces showed higher levels of broken glass fiber in vinyl ester compared to carbon vinyl ester composites. Suresha et al. [8] further states that specific wear rate of glass fabric reinforced vinyl ester composites is more than twice as compared to that of carbon fiber reinforced vinyl ester composites. It was observed that Young's modulus, Poisson's ratio, toughness and \% strain decreased with the increase of fiber orientation angle with respect to loading direction. In-plane shear modulus was highest for fibers with $45^{\circ}$. Overall unidirectional carbon fiber (CF) reinforcement enhanced all strength properties of PEI significantly. Composites with fibers in $0^{\circ}$ orientation proved best in almost all the properties $[9,10]$. The wear volume loss of the composites was found increasing with the increase in abrading distances and under the same conditions the specific wear rate decreases. The hard powders filled glass fabric-epoxy composite systems exhibit lower wear volume loss and lower specific wear rate as compared to unfilled glass fabricepoxy composite system [11-13].

Investigations have been done to study the effect of fiber/filler arrangement and/or mixing on the mechanical properties of hybrid composites. But relatively small amount of research reported in the literature has focused on the weave pattern, stacking sequence and percentage of fiber reinforcement of fabrics on the mechanical properties of hybrid composites. Our aim is to obtain better mechanical properties and reduced wear rate. In this paper bidirectional glass, carbon fabric will be used as reinforcement with thermosetting resin (epoxy) to manufacture hybrid composites to achieve more improved properties than that of single fiber type composites. To determine the correct sequence for the arrangement of glass fabric and carbon fabric various available stacking sequence are compared. An optimum value obtained from all mechanical properties gives us the value of best stacking sequence. For the available best stacking sequence the samples are then tested for mechanical and tribological properties.

\section{Experimental details}

\subsection{Material and method}

The hybrid polymer composite samples comprising of epoxy resin matrix reinforced with long (bidirectional) E-glass fabric (600 GSM) and long (bi-directional) carbon fabric (200 G.S.M, 3k-plain weave) in different weight percentages (10-50 wt.\% in steps of $10 \%)$. The glass fabric (young's modulus $72.5 \mathrm{GPa}$ and density $2,590 \mathrm{~kg} / \mathrm{m}^{3}$ ) was supplied by Saint Gobian and carbon fabric (young's modulus $123 \mathrm{GPa}$ and density $1,450 \mathrm{Kg} / \mathrm{m}^{3}$ ) was supplied by The Hindustan Technical Fabrics Limited, India. Epoxy resin (young's modulus $3.42 \mathrm{GPa}$ and density $1,100 \mathrm{~kg} / \mathrm{m}^{3}$ ) and hardener were supplied by Ciba Geigy India Ltd. The epoxy (LY-556) and hardener (HY-951) were mixed in the ratio of 10:1 by weight as recommended by supplier, thereafter alternate layers of glass fabric/carbon fabric and epoxy resin were arranged using hand-lay-up technique until the desired composition was obtained. Apply some weights and leave the composite for solidification at room temperature for 24 hours. After solidification composites were then removed from the mould and marking was done as per the sample dimensions. Thereafter, samples of appropriate dimensions were cut suiting to various studies.

\subsection{Specimen preparation}

\section{STEP-1: Based on stacking sequence}

Five types of hybrid laminates were prepared: First laminate was prepared with all the seven layers of glass fabric arranged one above the other (Fig. 1); second laminate was prepared with two layers of glass fabric at both the ends and remaining three layers of carbon fabric in between; third laminate was prepared with alternate layers of glass and carbon fabric; fourth laminate was prepared with two-two layers of carbon fabric at both the ends with remaining three layers of glass fabric in between the carbon fabric; and lastly fifth laminate was prepared with all the seven layers of carbon fabric arranged one above the other (Table 1). 


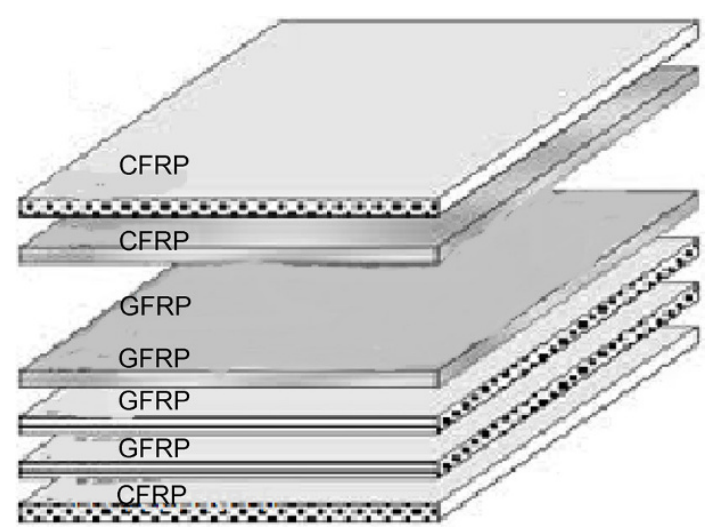

Fig. 1 Stacking sequence of CFRP and GFRP layers.

Table 1 Stacking sequence of bidirectional glass, carbon fabric in composite.

\begin{tabular}{ccccc}
\hline S. No & Code & $\begin{array}{c}\text { Stacking } \\
\text { Sequence }\end{array}$ & $\begin{array}{c}\text { Glass fabric } \\
\text { content }\end{array}$ & $\begin{array}{c}\text { Carbon fabric } \\
\text { content }\end{array}$ \\
\hline 1 & GC1 & G-G-G-G-G-G-G & $50 \%$ & $0 \%$ \\
2 & GC2 & G-G-C-C-C-G-G & $32 \%$ & $18 \%$ \\
3 & GC3 & G-C-G-C-G-C-G & $32 \%$ & $18 \%$ \\
4 & GC4 & C-C-G-G-G-C-C & $22 \%$ & $28 \%$ \\
5 & GC5 & C-C-C-C-C-C-C & $0 \%$ & $50 \%$ \\
\hline
\end{tabular}

Note: $\mathrm{G}$ - Glass fabric, $\mathrm{C}-$ Carbon fabric

These five different sequences of arrangement were used to determine the effect of fabric arrangement on the physical and mechanical properties of hybrid composites. Arrangement was also done to compare the properties of individual carbon and glass fabric arrangement with that of combined glass-carbon layers of fabric.

\section{STEP-2: Based on weight percent of fabric reinforced} Based on the results obtained from STEP-1 (alternate layers of glass and carbon fabric) stacking sequence was selected and five different percentages by weight of fabric composites were prepared. Five different percentages (10 wt. $\%, 20 \mathrm{wt} . \%, 30 \mathrm{wt} . \%, 40 \mathrm{wt} . \%$ and $50 \mathrm{wt} . \%)$ of fabric were reinforced with that of epoxy resin to notice the effect of weight percent of fabric reinforcement on the properties of composites (Table 2).

\subsection{Physical and mechanical characterization}

The theoretical density of the samples was computed using relation purposed by Agarwal and Broutman [14], i.e.,

$$
\rho_{\mathrm{ct}}=\frac{1}{\frac{W_{\mathrm{f}}}{\rho_{\mathrm{f}}}+\frac{W_{\mathrm{m}}}{\rho_{\mathrm{m}}}}
$$

where $W_{\mathrm{f}}$ and $W_{\mathrm{m}}$ are the weight fraction of fabric and matrix respectively, $\rho_{\mathrm{ct}}, \rho_{\mathrm{f}}$ and $\rho_{\mathrm{m}}$ are the density of the composite material, fabric and matrix resin. The experimental density $\left(\rho_{\mathrm{ex}}\right)$ was measured by simple water immersion technique. Thereafter, void fraction $(\Delta v)$ was computed by normalizing the differences in both densities against the theoretical density, i.e.,

$$
\Delta v=\left[\frac{\rho_{\mathrm{ct}}-\rho_{\mathrm{ex}}}{\rho_{\mathrm{ct}}}\right]
$$

The tensile strength, flexural strength and interlaminar shear strength (ILSS) were evaluated on universal testing machine (UTM) Instron 1195. The tensile test was done in accordance with ASTM D 3039-79 [15], and dimensions of tensile test specimen was $150 \mathrm{~mm} \times 15 \mathrm{~mm} \times 15 \mathrm{~mm}$. Flexural test was done on specimen having dimensions $150 \mathrm{~mm} \times 15 \mathrm{~mm} \times$ $15 \mathrm{~mm}$. Specimen was placed on the supports having span length of $50 \mathrm{~mm}$ and a cross head speed of $2.54 \mathrm{~mm} / \mathrm{min}$ was used with which load was applied on the specimen. Testing was done in accordance with ASTM D 2344-84 (ASTM D 256-97, 1984) test standards, while for ILSS [16] the specimen dimensions was $75 \mathrm{~mm} \times 15 \mathrm{~mm} \times 15 \mathrm{~mm}$, and span length of $30 \mathrm{~mm}$ at cross head speed of $2.54 \mathrm{~mm} / \mathrm{min}$ was taken.

Impact tests were done using plastic impact tester following ASTM D256 (ASTM D 256-97, 1999) test standards. Dimensions of the specimen used was $64 \mathrm{~mm} \times 12.7 \mathrm{~mm} \times 3.2 \mathrm{~mm}$, with $45^{\circ} \mathrm{V}$-shaped groove at $2 \mathrm{~mm}$ depth was used in between the specimen [17]. Micro-hardness measurement was done using a Leitz micro-hardness tester, equipped with a square based pyramidal (angle $136^{\circ}$ between opposite faces)

Table 2 Levels of the variables used.

\begin{tabular}{lccccc}
\hline \multirow{2}{*}{ Control factors } & \multicolumn{5}{c}{ Levels } \\
\cline { 2 - 6 } & I & II & III & IV & V \\
\hline Sliding velocity(A) & 48 & 72 & 96 & 120 & 144 \\
Fabric weight\% (B) & 10 & 20 & 30 & 40 & 50 \\
Normal load (C) & 20 & 40 & 60 & 80 & 100 \\
Sliding distance (D) & 50 & 60 & 70 & 80 & 90 \\
Abrasive size (E) & 125 & 250 & 375 & 500 & 625 \\
\hline
\end{tabular}


diamond indenter by applying a load of $24 \mathrm{~N}$. Vickers hardness number was calculated using the following equation,

$$
H_{\mathrm{v}}=0.1889 \frac{F}{L^{2}} \quad \text { and } \quad L=\frac{X+Y}{2}
$$

where $H_{\mathrm{v}}$ is the hardness, $F$ is the applied load, $L$ is the diagonal of the square impression and $X$ and $Y$ are the two diagonals of the diamond indenter. The surface morphology studies were performed on SEM CARL ZEISS NTS GMBH, SUPRA 40VP. The specimens were gold coated in order to enhance the conductivity of the samples, thereafter micrographs were taken for detail study of dynamics of wear mechanism.

\subsection{Experimental design}

Optimization was done to determine the effect of process parameters on the quality and optimal cost of the product. Parameters obtained from the Taguchi method can help us in deciding the best design. The Taguchi method reduces the number of iterations to solve the task; the taguchi method uses a special set of orthogonal arrays to solve the problem. Here Taguchi method of experimental approach was used to find optimum parameters from given five variables, viz., fabric content, normal load, sliding distance, abrasive size and sliding velocity as shown in Table 2 and each at five labels. The impact of five such parameters was studied using the $\mathrm{L}_{25}\left(5^{5}\right)$ orthogonal array design. Taguchi factorial experimental approach reduces the number of experiments to 25 runs, which in turn result in great reduction in effort and cost. The experimental observations were further transformed into signal to noise $(\mathrm{S} / \mathrm{N})$ ratios. The $\mathrm{S} / \mathrm{N}$ ratio for three body abrasion can be expressed as "lower is better", which was calculated as logarithmic transformation of loss function as shown below.

Smaller is the better characteristic:

$$
\frac{S}{N}=-10 \log \frac{1}{n}\left(\sum y^{2}\right)
$$

where $n$ is the number of observations and $y$ is the observed data.

As shown in Table 2, the first row is assigned to sliding velocity (A), second row to fabric weight percent (B), third to normal load (C), fourth to sliding distance (D) and fifth to abrasive particle size (E).

\section{Results and discussion}

Physical and mechanical properties of hybrid composites are discussed in two parts. The first part discussed the physical and mechanical properties of bidirectional glass fabric and carbon fabric reinforced epoxy composites based on stacking sequence, i.e., the arrangement of layers of different fabrics one above the other whereas the second part of mechanical properties is based on percentage of fabric reinforcement with that of matrix and it's over view. Finally, we have discussed the significant of factor settings and their effect on specific wear rate of the composites.

\subsection{Physical and mechanical properties}

3.1.1 Effect of stacking sequence on the void fraction of glass-carbon hybrid composites

The comparison between theoretical and experimental density of composites is shown in Table 3. As the density of fabric reinforcement increases, the volume fraction of void also tends to increase. Void fraction value represents the presence of pores and voids, i.e., the density of the composites. Presence of void directly or indirectly affects the mechanical properties of composites. Highest void fraction value of 5.156 is noticed in case of glass fabric laminate composites (GC1) whereas lowest void fraction value of 0.705 is noticed in case of hybrid composites (GC3) (Table 3). Void fraction values are higher when individual glass fabric and carbon fabric composites are used in comparison to that of hybrid composites.

Table 3 Comparison between Experimental density and theoretical density.

\begin{tabular}{ccccc}
\hline S.No. & $\begin{array}{c}\text { Composite } \\
\text { composition }\end{array}$ & $\begin{array}{c}\text { Experimental } \\
\text { density } \\
\left(\rho_{\mathrm{ex}}\right) \mathrm{g} / \mathrm{cm}^{3}\end{array}$ & $\begin{array}{c}\text { Theoretical } \\
\text { density } \\
\left(\rho_{\mathrm{ct}}\right) \mathrm{g} / \mathrm{cm}^{3}\end{array}$ & $\begin{array}{c}\text { Void fraction } \\
\Delta v\end{array}$ \\
\hline 1 & Epoxy $+\mathrm{GC} 1$ & 1.306 & 1.377 & 5.156 \\
2 & Epoxy $+\mathrm{GC} 2$ & 1.362 & 1.393 & 2.225 \\
3 & Epoxy $+\mathrm{GC} 3$ & 1.408 & 1.418 & 0.705 \\
4 & Epoxy $+\mathrm{GC} 4$ & 1.322 & 1.361 & 2.865 \\
5 & Epoxy $+\mathrm{GC} 5$ & 1.497 & 1.548 & 3.294 \\
\hline
\end{tabular}




\subsubsection{Effect of stacking sequence on the hardness of glass-carbon hybrid composites}

Figure 2 shows the effect of stacking sequence on the hardness of glass-carbon fabric reinforced epoxy composites. Maximum value of hardness is obtained for GC3 stacking sequence followed by GC2, GC4, GC1 and GC5, i.e., maximum value of hardness is obtained when alternate layers of glass and carbon fabric are arranged to form a composite and minimum value of hardness is obtained when layers of carbon fabrics alone are used for preparation of composites followed by individual layer of glass fabric alone are used for the preparation of composites, i.e, value of hardness increases when layers of glass fabric and carbon fabric are arranged in a certain pattern to form a composite whereas decreases when composites are prepared with either individual layers of glass fabric or carbon fabric.

3.1.3 Effect of stacking sequence on the tensile strength of glass-carbon hybrid composites

Figure 3 shows the effect of stacking sequence on the tensile strength of glass-carbon fabric reinforced epoxy composites. The tensile strength is more when combined layers of glass and carbon fabrics are used in comparison to that when individual layers of either glass fabrics or carbon fabrics are used for the preparation of composed. Highest tensile strength value for GC3 stacking sequence indicated that tensile strength is maximum when alternate layers of glass and carbon fabrics are used for the preparation of composites and this may be due to better bonding achieved between the layers of glass-carbon fabrics with that of epoxy. Minimum value of tensile strength is obtained when composite are prepared with individual layers of glass fabrics. The descending order of tensile strength is GC3>GC4>GC2>GC5>GC1.

3.1.4 Effect of stacking sequence on the flexural strength of glass-carbon hybrid composites

Figure 4 shows the effect of stacking sequence on the flexural strength of glass-carbon fabric hybrid composites. On comparing flexural strength of glasscarbon hybrid composites with individually layers of glass fabric reinforced epoxy composites and carbon fabric reinforced epoxy composites it has been

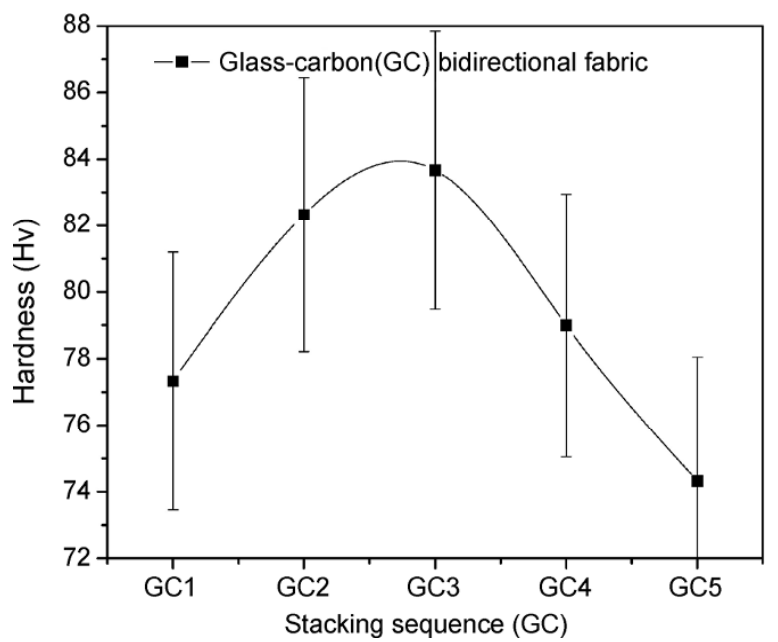

Fig. 2 Effect of stacking sequence (GC) on hardness of the composites.

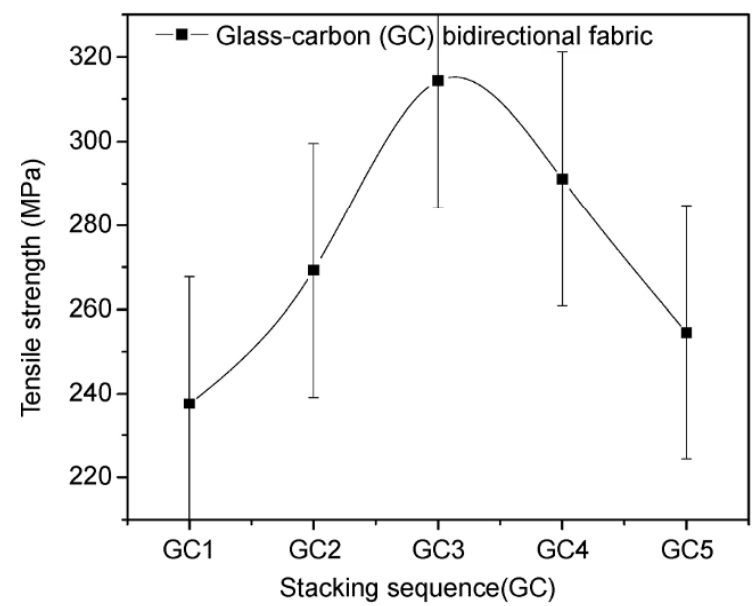

Fig. 3 Effect of stacking sequence (GC) on tensile strength of the composites.

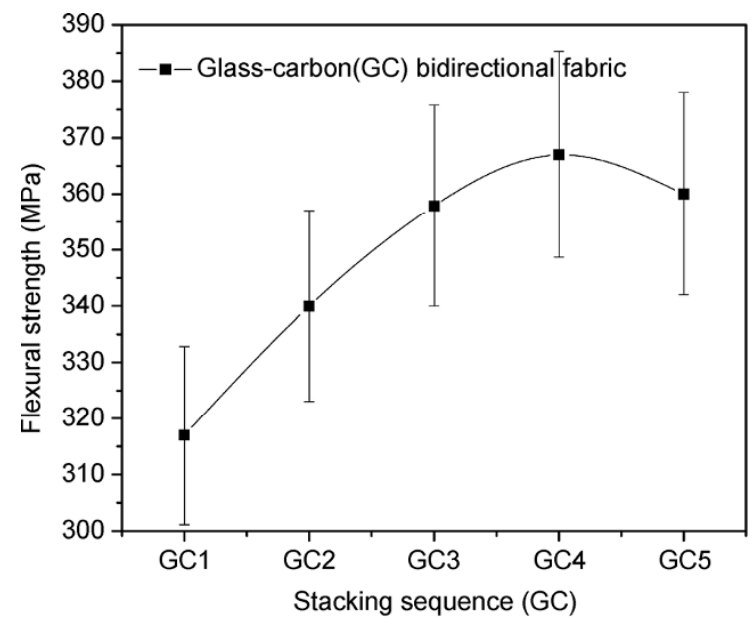

Fig. 4 Effect of stacking sequence (GC) on flexural strength of the composites. 
observed that the flexural strength values are higher when the carbon fabrics are at the extreme ends followed by glass-carbon fabric reinforced epoxy composites. The lowest value of flexural strength is obtained when individually glass fabrics are used for the preparation of composites. The reason for the decrease in flexural strength when glass fabrics are at the extreme ends is that in case of flexural loading extreme outer layers are subjected to tension and compression and due to the brittle nature of glass fabrics, fracture propagates easily in case of glass fabrics in comparison to that of carbon fabrics. Ary Subagia and Kim [18] also observed similar findings while studied flexural strength properties of carbon-basalt/epoxy hybrid composites. The descending order of flexural strength of the five compositions is GC4>GC5>GC3> GC2>GC1.

\subsubsection{Effect of stacking sequence on ILSS of glass-carbon hybrid composites}

Inter-laminar shear strength (ILSS) is useful test for composites where the chances for failure of lamina initiate when subjected to shearing stresses. Figure 5 shows the ILSS values for five different compositions, and ILSS values are higher in case of glass-carbon hybrid composites in comparison to that of glass fabric laminate composites and carbon fabric laminate composites. Better interfacial bonding is achieved when carbon fabrics are used with that of glass fabrics. The decreasing order of ILSS of five different tested composites is as follows GC2>GC4>GC3>GC1>GC5.

\subsubsection{Effect of stacking sequence on impact strength of glass-carbon hybrid composites}

Figure 6 shows the impact strength values of glasscarbon fabric reinforced epoxy composites. Reverse trend in the values is observed while determining the effect of stacking sequence on the impact strength of glass-carbon fabric hybrid composites. Highest value of impact strength is noticed when glass fabric laminate composites or carbon fabric laminate composites are used for the preparation of composites. Higher values of impact strength are noticed for GC4 composition, which is due to the presence of higher void fraction inside the composites. The decreasing order of impact strength is as follows: GC1>GC4>GC5>GC3>GC2.

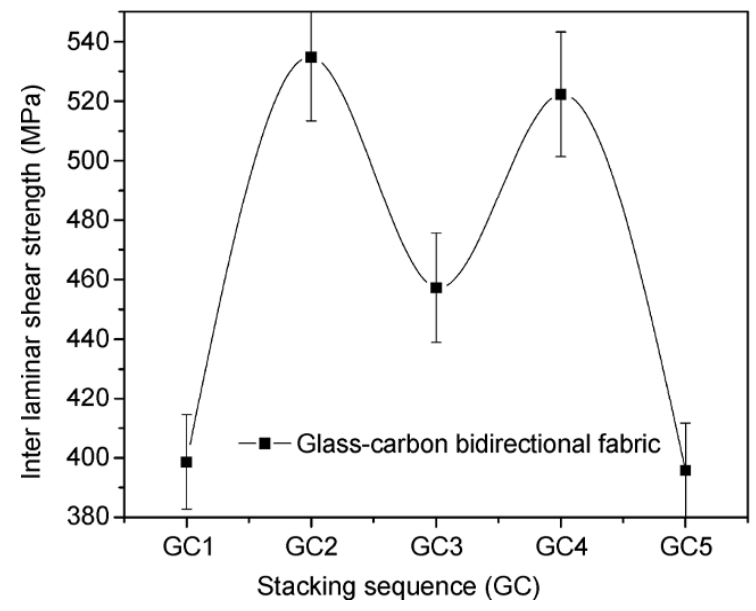

Fig. 5 Effect of stacking sequence (GC) on ILSS of the composites.

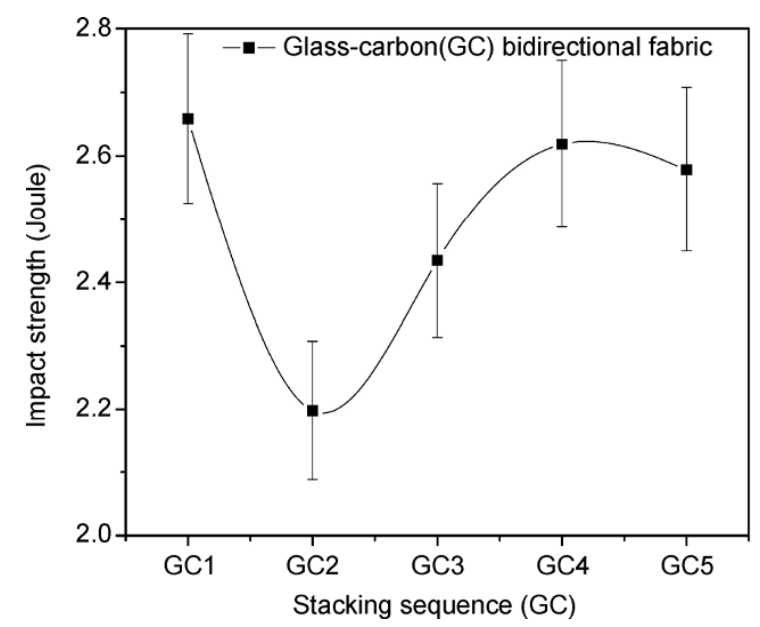

Fig. 6 Effect of stacking sequence (GC) on impact strength of the composites.

Based on the above discussion to determine best stacking sequence for glass/carbon fabric hybrid composite, the best stacking sequence (position and orientation) is for GC4, i.e., when two layers of carbon fabric are at both the extreme ends and remaining three layers of glass fabric are in between the carbon fabric layers. The position and sequence of arrangement of fabric in which the properties comes second is for GC3, i.e., when alternate layers of glass and carbon fabrics are arranged in the sequence followed by GC2, GC5 and GC1.

\subsection{Effect of percentage of fabric reinforcement on the mechanical properties of glass-carbon hybrid composites}

Table 4 shows the effect of percentage of fabric 
Table 4 Mechanical properties glass-carbon hybrid composite based on percentage of fabric reinforcement.

\begin{tabular}{cccccc}
\hline Composition & $\begin{array}{c}\text { T.S } \\
(\mathrm{MPa})\end{array}$ & $\begin{array}{c}\text { F.S } \\
(\mathrm{MPa})\end{array}$ & $\begin{array}{c}\text { I.L.S.S } \\
(\mathrm{MPa})\end{array}$ & $\begin{array}{c}\text { I.S } \\
(\mathrm{J})\end{array}$ & $\begin{array}{c}\text { Hardness } \\
(\mathrm{HV})\end{array}$ \\
\hline $10 \% \mathrm{GF} / \mathrm{CF}$ & 278.1 & 443 & 410.12 & 1.910 & 73.1 \\
$20 \% \mathrm{GF} / \mathrm{CF}$ & 283.7 & 397.1 & 429.76 & 2.861 & 77.9 \\
$30 \% \mathrm{GF} / \mathrm{CF}$ & 317.1 & 373.6 & 420.22 & 3.387 & 81.2 \\
$40 \% \mathrm{GF} / \mathrm{CF}$ & 340.9 & 316.6 & 417.23 & 3.730 & 81.9 \\
$50 \% \mathrm{GF} / \mathrm{CF}$ & 359.6 & 249.2 & 431.11 & 4.512 & 84 \\
\hline
\end{tabular}

reinforcement on the mechanical properties (tensile strength, flexural strength, inter laminar shear strength, impact strength and hardness) of glass-carbon fabric reinforced epoxy composites. Increases in the values of mechanical properties are noticed with the increase in the percentage of fabric reinforcement except that in case of flexural strength where increase in the percentage of fabric reinforcement results in decrease in the percentage of flexural strength (Table 4). Decrease in the percentage of fabric reinforcement may be attributed to the fact that with the increase in the percentage of fabric reinforcement alternate layers of glass and carbon fabrics increase and due to improper bonding between the layers of glass and carbon flexural strength in turn decrease. Inter laminar shear strength shows no appreciable change in the values of with the increase in the percentage of fabric reinforcement. Nigel and Brown [19] also determine similar findings while determining flexural and interlaminar shear properties of glass reinforced phenolic composite.

Tensile strength increases with the increase in the percentage of fabric reinforcement (Table 4). This is because that the percentage of fabrics increases proper bonding is achieved between the layers of fabrics and resin (epoxy). Increase in the percentage of fabric reinforcement also results in increase in value of impact strength and hardness of the composites (Table 4). As fabrics works as a medium for the transfer and distribution of loads from one end to another, i.e., as the number of fabrics increases the load can effectively be transferred from one end to another resulting in increase in impact absorbing capacity of the material. Increase in hardness is due to the fact that as the percentage of fabric reinforcement increases the structure becomes denser and compact, therefore hardness of the composite specimen increases.

\subsection{Analysis of experimental results by Taguchi experimental design}

In Table 5, the eighth column represents $\mathrm{S} / \mathrm{N}$ ratio of the specific wear rate of the composites which is in fact the average of two replications. The overall mean for the $\mathrm{S} / \mathrm{N}$ ratio of the specific wear rate is found to be $29.97 \mathrm{db}$ for hybrid glass-carbon reinforced epoxy based composites. The analysis was made using MINITAB 15 software used for design of experiment applications. It is observed that the abrasive result leads to the conclusion that factor combination of $\mathrm{A}_{2}$ $\mathrm{B}_{3}, \mathrm{C}_{4}, \mathrm{D}_{5}$ and $\mathrm{E}_{1}$ gives minimum specific wear rate for hybrid glass-carbon-epoxy composites. It is observed that abrasive particle size plays dominant role followed by sliding velocity, fabric percentage, normal load and sliding distance, i.e., sliding distance have comparatively negligible effect in the specific wear rate of the composites (Fig. 7).

\subsection{ANOVA and the effects of factors}

Analysis of variance (ANOVA) based on Taguchi experimental results is performed in order to find out statistical significance of various factors like sliding velocity, fabric loading, normal load, sliding distance and abrasive size on specific wear rate of hybrid. Experimental analysis of ANOVA is done using MINITAB 15 software. Tables 6 and 7 show the results of the ANOVA with the specific wear rate of composites taken in this investigation. This analysis is undertaken for a level of confidence of significance of $5 \%$. The last column of the table indicates that the main effects are highly significant (all have very small $p$-values) (Table 6, Column 7).

From Table 6, it can be observed for hybrid glasscarbon epoxy based composites that sliding velocity $(p=0.032)$ and normal load $(p=0.171)$ have a great influence on specific wear rate (having lower $p$ values). However abrasive particle size $(p=0.217)$, fabric loading ( $p=0.238)$ and sliding distance $(p=0.340)$ shows less significant contribution (having higher $p$ values) on specific wear rate of the composites. Therefore, from this analysis it is clear that percentage of sliding velocity and normal load are more suitable for glasscarbon hybrid composites.

Table 7 shows the response table for signal to noise 
Table 5 Experimental design using $\mathrm{L}_{25}$ orthogonal array.

\begin{tabular}{|c|c|c|c|c|c|c|c|}
\hline \multirow[b]{2}{*}{$\begin{array}{l}\text { Expt. } \\
\text { No. }\end{array}$} & \multirow[b]{2}{*}{$\begin{array}{l}\text { Sliding velocity } \\
(\mathrm{cm} / \mathrm{s})\end{array}$} & \multirow[b]{2}{*}{$\begin{array}{l}\text { Fabric loading } \\
\quad(\mathrm{GF} / \mathrm{CF})\end{array}$} & \multirow[b]{2}{*}{$\begin{array}{l}\text { Normal load } \\
\text { (N) }\end{array}$} & \multirow[b]{2}{*}{$\begin{array}{l}\text { Siding distance } \\
(\mathrm{m})\end{array}$} & \multicolumn{3}{|c|}{ Ws glass-carbon } \\
\hline & & & & & $\begin{array}{l}\text { Abrasive particle } \\
\text { size }(\mu \mathrm{m})\end{array}$ & $\left(\frac{\mathrm{mm}^{3}}{\mathrm{~N} \cdot \mathrm{m}}\right)$ & $\begin{array}{l}\mathrm{S} / \mathrm{N} \text { ratio } \\
\text { glass }(\mathrm{db})\end{array}$ \\
\hline 1 & 48 & 10 & 20 & 50 & 125 & 0.023520 & 32.5713 \\
\hline 2 & 48 & 20 & 40 & 60 & 250 & 0.363960 & 28.7789 \\
\hline 3 & 48 & 30 & 60 & 70 & 375 & 0.574480 & 29.8145 \\
\hline 4 & 48 & 40 & 80 & 80 & 500 & 0.710070 & 28.9740 \\
\hline 5 & 48 & 50 & 100 & 90 & 625 & 0.029321 & 30.6564 \\
\hline 6 & 72 & 10 & 40 & 70 & 500 & 0.029810 & 30.5128 \\
\hline 7 & 72 & 20 & 60 & 80 & 625 & 0.037004 & 28.6350 \\
\hline 8 & 72 & 30 & 80 & 90 & 125 & 0.021312 & 33.0292 \\
\hline 9 & 72 & 40 & 100 & 50 & 250 & 0.034676 & 29.1994 \\
\hline 10 & 72 & 50 & 20 & 60 & 375 & 0.023340 & 32.6380 \\
\hline 11 & 96 & 10 & 60 & 90 & 250 & 0.034380 & 29.2739 \\
\hline 12 & 96 & 20 & 80 & 50 & 375 & 0.042290 & 27.4752 \\
\hline 13 & 96 & 30 & 100 & 60 & 500 & 0.043890 & 27.1527 \\
\hline 14 & 96 & 40 & 20 & 70 & 625 & 0.032380 & 29.7945 \\
\hline 15 & 96 & 50 & 40 & 80 & 125 & 0.025437 & 31.8907 \\
\hline 16 & 120 & 10 & 80 & 60 & 625 & 0.039467 & 28.0753 \\
\hline 17 & 120 & 20 & 100 & 70 & 125 & 0.033240 & 29.5668 \\
\hline 18 & 120 & 30 & 20 & 80 & 250 & 0.023280 & 32.6603 \\
\hline 19 & 120 & 40 & 40 & 90 & 375 & 0.041110 & 27.7211 \\
\hline 20 & 120 & 50 & 60 & 50 & 500 & 0.049810 & 26.0537 \\
\hline 21 & 144 & 10 & 100 & 80 & 375 & 0.023430 & 32.6046 \\
\hline 22 & 144 & 20 & 20 & 90 & 500 & 0.025650 & 31.8183 \\
\hline 23 & 144 & 30 & 40 & 50 & 625 & 0.029720 & 30.5390 \\
\hline 24 & 144 & 40 & 60 & 60 & 125 & 0.031991 & 29.8994 \\
\hline 25 & 144 & 50 & 80 & 70 & 250 & 0.031800 & 29.9515 \\
\hline
\end{tabular}

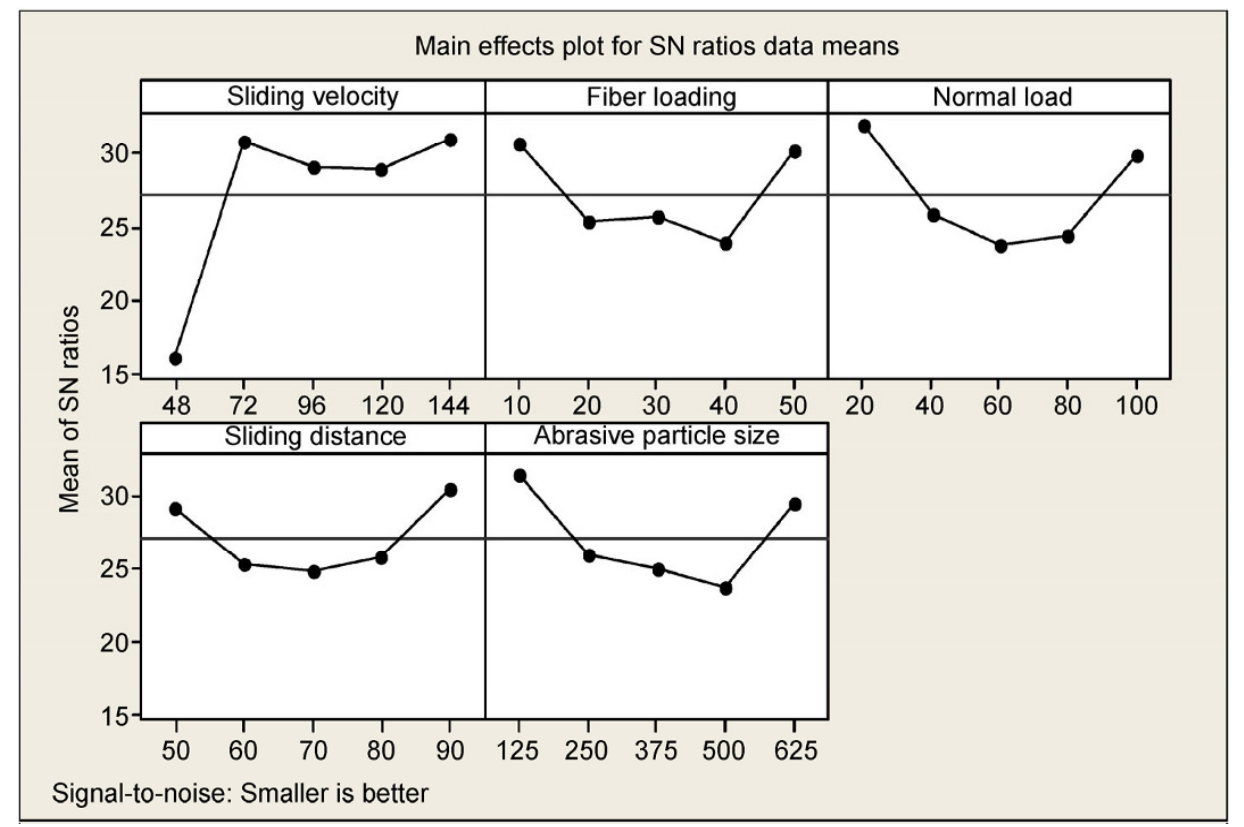

Fig. 7 Effect of control factors on signal to-noise ratio of hybrid glass-carbon fabric. 
Table 6 ANOVA table for specific wear rate (glass-carbon hybrid composite).

\begin{tabular}{ccccccc}
\hline Source & DF & Seq SS & Adj SS & Adj MS & F & P \\
\hline A & 4 & 798.8 & 798.8 & 199.7 & 6.78 & 0.032 \\
B & 4 & 189.1 & 189.1 & 47.26 & 1.60 & 0.238 \\
C & 4 & 255.5 & 255.5 & 63.89 & 2.17 & 0.171 \\
D & 4 & 127.8 & 127.8 & 31.96 & 1.08 & 0.340 \\
E & 4 & 206.9 & 206.9 & 51.73 & 1.76 & 0.217 \\
Error & 4 & 117.9 & 117.9 & 29.47 & & \\
Total & 24 & 790.14 & & & & \\
\hline
\end{tabular}

Table 7 Response table for signal to noise ratio (smaller is better).

\begin{tabular}{cccccc}
\hline Level & $\begin{array}{c}\text { Sliding } \\
\text { Velocity }\end{array}$ & $\begin{array}{c}\text { Fabric } \\
\text { loading }\end{array}$ & $\begin{array}{c}\text { Normal } \\
\text { load }\end{array}$ & $\begin{array}{c}\text { Sliding } \\
\text { distance }\end{array}$ & $\begin{array}{c}\text { Abrasive } \\
\text { particle size }\end{array}$ \\
\hline 1 & 15.96 & 30.61 & 31.90 & 29.17 & 31.39 \\
2 & 30.80 & 25.25 & 25.89 & 25.31 & 25.97 \\
3 & 29.12 & 25.64 & 23.74 & 24.93 & 25.05 \\
4 & 28.82 & 23.92 & 24.30 & 25.75 & 23.70 \\
5 & 30.96 & 30.24 & 29.84 & 30.50 & 29.54 \\
Delta & 15.00 & 6.69 & 8.16 & 5.57 & 7.69 \\
Rank & 1 & 4 & 2 & 5 & 3 \\
\hline
\end{tabular}

ratio. Rank of various factors is defined based on their contribution in three body specific wear rate analysis. Sliding velocity is ranked first followed by normal load, abrasive particle size, fabric loading and sliding distance.

\subsection{Surface morphology}

Three body abrasion is the phenomenon in which specimen in fixed in the specimen holder and chlorobutyl rubber wheel moves against the surface of the specimen. Free flowing abrasive particles pass in between the specimen and the rubber wheel and in turn create the scenario of three body abrasion. Figure 8(a) shows the surface micrograph of $10 \mathrm{wt} . \%$ fabric reinforced glass-carbon hybrid composites. From the figure it is clearly shown that matrix material due to its brittle nature chips off faster than the fabrics, and carbon fabric is clearly shown in the SEM micrographs. For lower sliding velocity (sliding velocity $-48 \mathrm{~cm} / \mathrm{s}$, normal load $-20 \mathrm{~N}$ and sliding distance-50 $\mathrm{m}$ ) and smaller abrasive particle size $(125 \mu \mathrm{m})$ the amount of wear is less (as shown in Fig. 8(a)).
Figure 8(b) shows the surface micrograph at $20 \mathrm{wt} . \%$ fabric reinforcement. Here fabrics are exposed to the atmosphere which clearly indicated that fabrics are used to provide hardness and strength to the matrix. Matrix provide the medium for the arrangement of the fabrics in the medium and fabrics transfer loads, fabrics transfer loads among themselves and hence provide strength to the composite. At $72 \mathrm{~cm} / \mathrm{s}$ sliding velocity, $60 \mathrm{~N}$ normal load and $625 \mu \mathrm{m}$ abrasive particle size the amount of wear increases because bigger size abrasive particles remove more of material resulting in higher wear rate. Figure $8(\mathrm{~b})$ clearly shows the amount of wear mechanism involved and protudement of fiber parts/ends from the composite. The dominant wear mechanisms are fracture and grain pull-out.

Figure 8(c) shows the surface micrograph at $30 \mathrm{wt} . \%$ fabric reinforcement. Photo micrograph is taken for $100 \mathrm{~N}$ normal load and $500 \mu \mathrm{m}$ abrasive particle size. Due to higher normal load, fabrics are subjected brittle fracture and ends or part of the fabrics are removed during three body abrasion. Right part of the SEM micrograph clearly shows that fibers are detached from the matrix and ends of the fibers are subjected to fracture.

Bigger abrasive particle size also results in increased wear rate as the particles when embedded inside the surface of the specimen. Figure 8(c) represents that
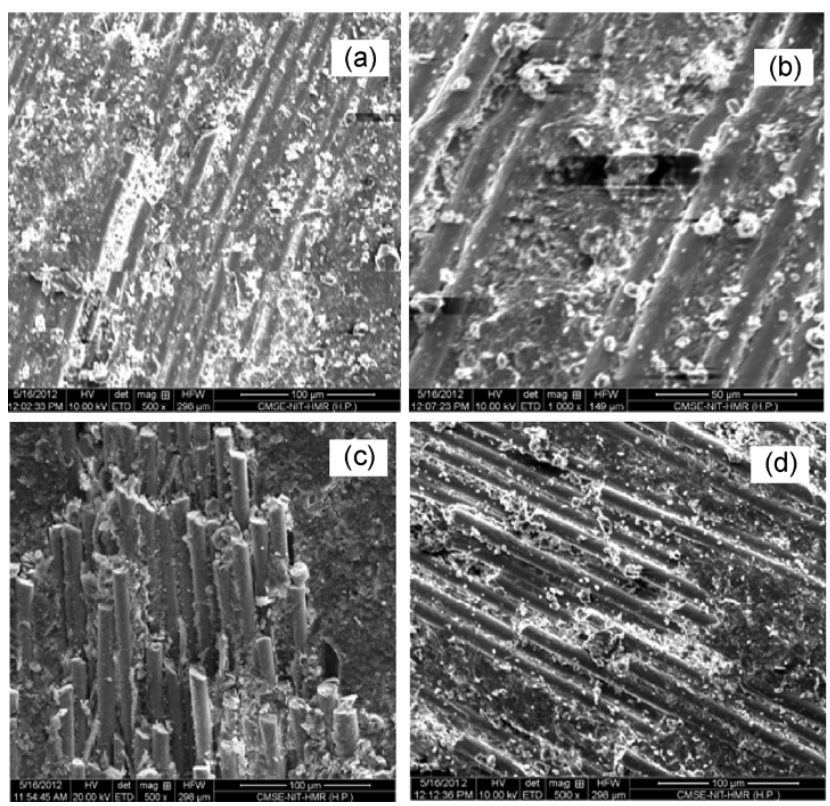

Fig. 8 SEM micrographs of the wear details of glass-carbon fabric reinforced epoxy composites. 
part of fabrics are broken and chipped off results in higher specific wear rate. Figure $8(\mathrm{~d})$ shows the surface micrograph for $40 \mathrm{wt} . \%$ fabric reinforcement, due to smaller abrasive particle size $(125 \mu \mathrm{m})$ and lower sliding velocity $(72 \mathrm{~m} / \mathrm{s})$ part of the matrix material (epoxy) from the surface is removed result in fabrics exposed to the environment.

\section{Conclusion}

Based on the above analysis carried out on glasscarbon hybrid composites to investigate the effect of fabric reinforcement, position, orientation on the physical, mechanical, and tribological properties of composites, the following points can be concluded as below:

1. The best stacking sequence (position and orientation) is for GC4, i.e., when two-two layers of carbon fabric are at the extreme ends and remaining three layers of glass fabric are in between the carbon fabric layers.

2. Percentage of fabric reinforcement of glass-carbon hybrid composites has significant effect on mechanical properties of the composites. Mechanical properties such as tensile strength, impact strength and hardness increases with the increase in fabric reinforcement from $10 \mathrm{wt} . \%$ to $50 \mathrm{wt} . \%$.

3. The values of flexural strength decreases with the increase in percentage of fabric reinforcement whereas slight increase/decrease in ILSS values are noticed with the increase in the percentage of fabric reinforcement, i.e., by analyzing the entire graph it is clear that the ILSS values nearly remains same.

4. In Taguchi experimental analysis it has been observed that composites having factor combination of $\mathrm{A}_{2}, \mathrm{~B}_{3}, \mathrm{C}_{4}, \mathrm{D}_{5}$ and $\mathrm{E}_{1}$ (where $\mathrm{A}, \mathrm{B}, \mathrm{C}, \mathrm{D}$ and $\mathrm{E}$ are denoted in Table 2) give minimum specific wear rate.

5. Experimental analysis of test results revealed that sliding distance $(p=0.340)$ and fabric loading $(p=$ 0.238 ) have greater influence on specific wear rate whereas other factors have relatively lower significant contribution.

6. From the analysis of SEM micrographs it has been revealed that cracking and fracture are the dominant wear mechanism due to which the wear rate of the composites increases.

7. In future the study can be extended to new polymer composites having different fabric/matrix combinations and the resulting experimental findings can be further analyzed.

Open Access: This article is distributed under the terms of the Creative Commons Attribution License which permits any use, distribution, and reproduction in any medium, provided the original author(s) and source are credited.

\section{References}

[1] Ho K K C, Qian H, Bismarch A. Surface properties of carbon fiber. Wiley Encyclpedia of Composites, $2^{\text {nd }} \mathrm{Ed}$, Nicolais L and Borzacchiello A. John Wiley and Sons, Inc. 2012.

[2] Zhao J, Ho K K C, Shamsuddin S R, Bismarch A, Dutschk V. A comparative study of fiber/matrix interface in glass fiber reinforced polyvinylidene fluoride composites. Collid Surface A 413: 58-64 (2012)

[3] Stachowiak G W, Batchelor A W. Engineering Tribology. Butterworth Heinemann, 1998.

[4] Gururaja M N, Rao A N H. A review on recent applications and future prospects of hybrid composites. International Journal of Soft Computing and Engineering 1(6): 352-355 (2012)

[5] Cirino M, Friedrich K, Pipes R B. The abrasive wear behavior of continuous fiber polymer composites. J Mater Sci 22: 2481-2492 (1887)

[6] Hayashi T. On the improvement of mechanical properties of composites by hybrid composition. In Proceedings of the Eighth International Reinforced Plastics Conference, 1972.

[7] Suresha B, Kumar K S, Seetharamu S, Kumaran P S. Friction and dry sliding wear behavior of carbon and glass fabric reinforced vinyl ester composites. Tribol Int 43(3): 602-609 (2010)

[8] Suresha B, Kunigal N, Kumar S. Investigations on mechanical and two-body abrasive wear behavior of glass/carbon fabric reinforced vinyl ester composite. Mater Design 30(6): 20562060 (2009)

[9] Sharma M, Rao I M, Bijwe J. Influence of fiber orientation on abrasive wear of unidirectionally reinforced carbon fiberpolyetherimide composites. Tribol Int 43(5-6): 959-964 (2010)

[10] Agarwal G, Patnaik A, Sharma R K. Parametric optimization of three-body abrasive wear behavior of long and short carbon fibre reinforced epoxy composites. Tribology Material, Surface and Interfaces 7(3): 150-160 (2013)

[11] Chand N, Gautam K K S. Influence of load on abrasion fly- 
ash glass fiber reinforced composites. J Mater Sci Lett 13: 230-233 (1994)

[12] Agarwal G, Patnaik A, Sharma R K. Thermo-mechanical properties of silicon carbide filled chopped glass fiber reinforced epoxy composites. International journal of Advanced Structural Engineering 5(21): 1-8 (2013)

[13] Mohan N, Natarajan S, KumareshBabu S P. Abrasive wear behavior of hard powders filled glass fabric-epoxy hybrid composites. Mater Design 32(3): 1704-1709 (2000)

[14] Agarwal B D, Broutman I J. Analysis and Performance of Fiber Composites, $2^{\text {nd }}$ ed. New York: Wiley, 1990.

[15] Tensile properties of fiber-resin composites. ASTM D 3039-76 (1976)

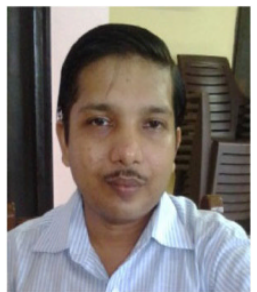

Gaurav AGARWAL. He has graduated in Mechanical Engineering from Jawaharlal Nehru National College of Engineering and completed post graduation from Career Institute of Technology and Mana-

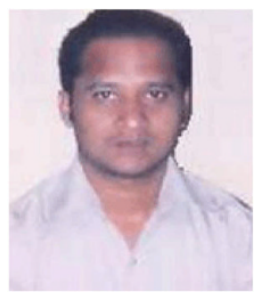

Amar PATNAIK. He is an assistant professor in the department of Mechanical Engineering at NIT Hamirpur. He received his $\mathrm{PhD}$ degree in composite material form

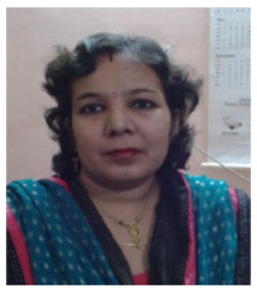

Jyoti AGARWAL. She has graduated in Computer Science and Engineering from SRMSCET, Bareilly and completed post graduation from NITTR Chandigarh. Currently
[16] Standard test method for apparent inter-laminar shear strength for parallel fiber composites by short beam method. ASTM D 2344-84 (1984)

[17] Standard test methods for determining the pendulum impact resistance of notched specimens of plastic. ASTM D 256-97 (1999)

[18] Ary Subagia I D G, Kim Y. A study on flexural properties of carbon basalt / epoxy hybrid composites. J Mech Sci Tech 27(4): 987-992 (2013)

[19] Nigel S J, Brown J R. Flexural and inter laminar shear properties of glass reinforced phenolic composite. Composites: Part A 29: 939-946 (1998)

gement, Faridabad. Recently he has completed his PhD degree in polymer matrix composite from NIT Hamirpur. Currently he is working as an associate professor in Mechanical Engineering department of Invertis University, Bareilly, India

NIT Rourkela. He has a very strong background in the area of tribology, friction and wear. Under his guidance number of research scholars has submitted their M.Tech and PhD degrees.

she is working as an assistant professor in Computer Science and Engineering Department of RIMT, Bareilly, India. Her research interests lie in the area of Network security, simulation and modeling techniques. 